\title{
Partner support, social-cognitive variables and their role in adherence to self-monitoring of blood glucose in type 2 diabetes
}

\author{
Vera Costa, $\mathrm{Dr}^{1}$ \\ M Graça Pereira, $\mathrm{PhD}^{1}$ \\ Susana Pedras, MPsy ${ }^{1}$ \\ ${ }^{1}$ University of Minho, School of Psychology, \\ Portugal

\begin{abstract}
Correspondence to: Vera Costa, Psicologia, Campus de Gualtar, 4710-057

Braga, Portugal; email: vera.asc@gmail.com
\end{abstract} \\ Universidade do Minho, Escola de
}

Received: 30 January 2012

Accepted in revised form: 7 June 2012

\section{Introduction}

The prevalence of diabetes is alarmingly increasing worldwide, reaching about $8.3 \%$ of the adult population, and it is expected that, in 2030, one adult in 10 will have diabetes. ${ }^{1}$ In Portugal, $11.7 \%$ of the population have diabetes and $23.2 \%$ have prediabetes. $^{2}$ In 2008, diabetes expenditure was $7 \%$ of the state budget for health and $0.7 \%$ of the Portuguese Gross Domestic Product. ${ }^{3}$

Diabetes, as a chronic disease, implies adherence, on a daily basis, to diet, physical activity, medication, foot care and self-monitoring of blood glucose (SMBG). Integration of these behaviours in the daily routine may be too demanding for the patient, due to the complexity of the regimen that requires several tasks and frequent decisions regarding the treatment. ${ }^{4,5}$ Furthermore, treatment adherence may be influenced by several factors, including spousal support and social-cognitive variables, such as the constructs of the Theory of Planned Behaviour (TPB) (attitudes, subjective norms, perceived behaviour control and intentions), and action and coping planning. In

\begin{abstract}
Summary
In Portugal, diabetes affects $11.7 \%$ of the population, of whom about $90 \%$ have type 2 diabetes. Patients and their partners are affected and the latter have a direct impact on patients' adaptation to diabetes. A large proportion of patients, at diagnosis, have to readjust their daily routines in order to integrate self-care behaviours related to diabetes.

The goal of this study was to analyse the relationship among partner support, social-cognitive variables about self-monitoring of blood glucose (SMBG) (intentions, attitudes, subjective norms, perceived behaviour control, action planning and coping planning), adherence and glycaemic control in type 2 diabetes patients, diagnosed in the past 12 months.

A total of 179 people with diabetes participated in the study. The instruments used were: Multidimensional Diabetes Questionnaire; Revised Summary of Diabetes Self-Care Activities Scale; and Planned Behavior Questionnaire - Self-Monitoring of Blood Glucose. Glycaemic control was assessed by $\mathrm{HbA}_{1 \mathrm{c}}$.

The perception of positive support from partners and intention to perform SMBG predicted adherence to SMBG. Furthermore, positive support mediated the relationship between intention and adherence to SMBG. Positive and negative partner support were positively associated with intention, action and coping planning and adherence to SMBG. Good metabolic control was negatively associated with negative support.

The results show the importance of partners' support and social-cognitive variables, regarding self-monitoring of blood glucose, on patients' adherence.
\end{abstract}

Eur Diabetes Nursing 2012; 9(3): 81-86

\section{Key words}

diabetes; adherence; self-monitoring of blood glucose

fact, TPB has been used to predict and change health-related behaviours, ${ }^{6,7}$ as well as to develop and evaluate interventions in health behaviour change. ${ }^{8}$ In diabetes, TPB has been used in particular to enable a better understanding of multiple behaviours related to adherence, such as physical activity, pharmacotherapy and nutritional care. ${ }^{9}$

According to TPB ${ }^{10-12}$ (Figure 1), the intention to perform a particular behaviour and, consequently, the behaviour itself, is dependent on attitudes towards the behaviour, subjective norms and perceived behavioural control. Attitudes are the favourable or unfavourable evaluation regarding the performance of a particular behaviour and are determined by beliefs about the consequences that may arise from the performance of such behaviour (behavioural beliefs), and by the assessment of the desirability of those consequences. Subjective norms refer to perceived social pressure to perform, or not, a particular behaviour. The contribution of significant others' opinions is dependent on individuals' motivation to act in accordance with the wishes of the referent. Perceived behavioural control represents the personal perception of ease or difficulty in performing a given behaviour. This construct reflects, in some way, the individual ability to perform a specific behaviour, and resources and opportunities available dictate, to some extent, the likelihood of implementing the behaviour. ${ }^{10}$

Consistent with the objective of explaining human behaviour, besides predicting it, TPB deals with 


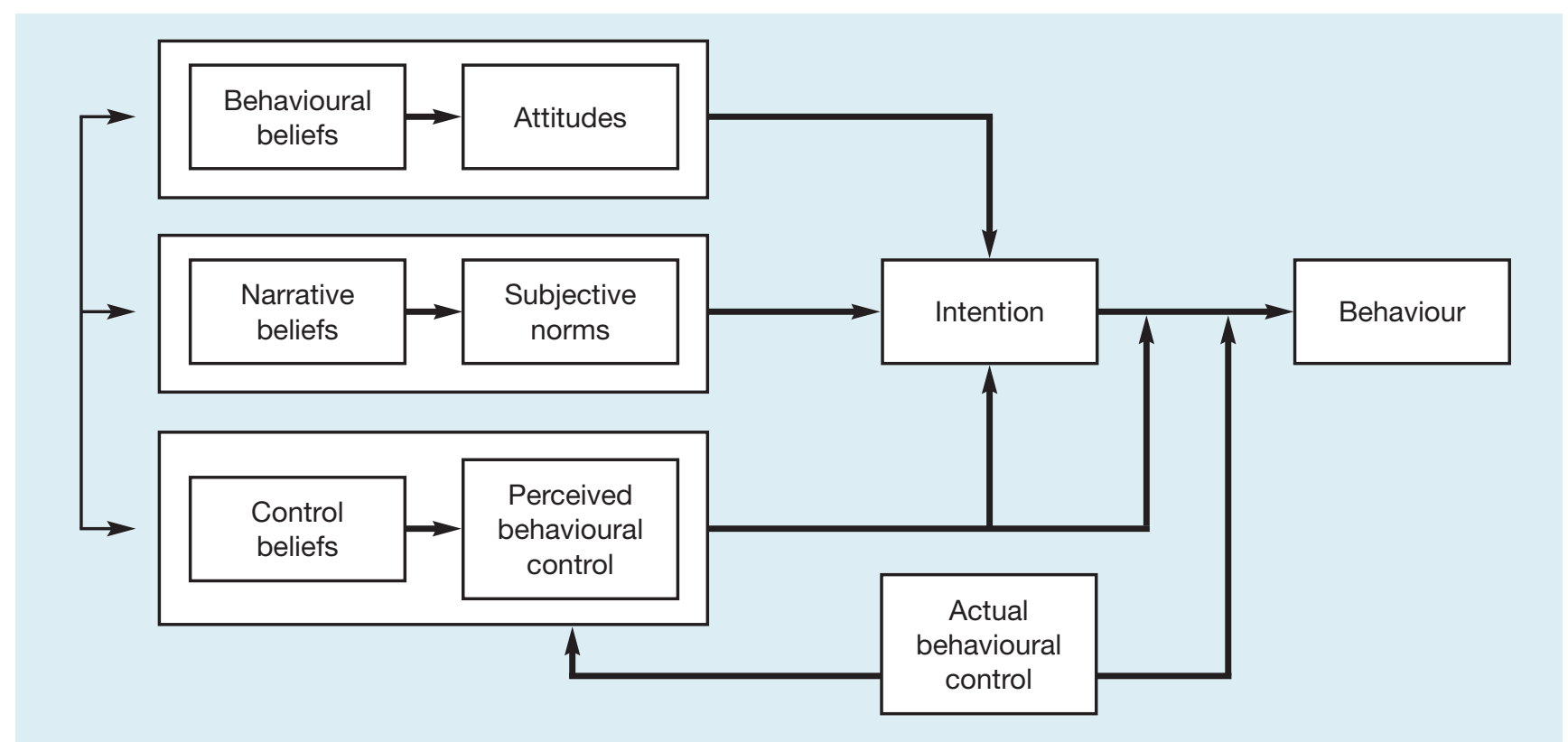

Figure 1. Theory of Planned Behaviour (based on Ajzen, 1985'2)

attitudes (behavioural beliefs), subjective norms (normative beliefs) and perceived behavioural control (beliefs of control) that, in the final analysis, determine the intentions and behaviour. ${ }^{10-12}$

The influence of spousal support is very significant and important for couples who have to deal with a chronic illness, ${ }^{13}$ and appears to be even more significant in couples where one of the spouses has diabetes, because diabetes care often involves the spouse (e.g. buying and preparing food, medication administration, and involvement in physical exercise).$^{13}$ Previous studies suggest that the most important behaviours in treatment adherence, from spouses, are positive support, encouragement, praise, and reminding and helping the patient to plan. Criticism and pressure are not associated with positive outcomes. ${ }^{14-16}$

Stephens et al. ${ }^{17}$ found two types of negative and positive social control strategies, i.e. warning and encouragement, used by spouses to urge patients with type 2 diabetes to improve adherence to diet. Both spousal warning and encouragement were associated with patients' adherence to the recommended diet, with warning (regarding active involvement in diet, diabetes complications, adherence, dietary information, doubts or concerns) being associated with poorer adherence and, on the other hand, encouragement (regarding active involvement in diet, adoption of appropriate diet, the consumption of healthy foods, compliments on dietary management) being associated with better adherence. In fact, patients' dietary behaviour appears to be best served when the spouse uses more positively toned and less coercive influence attempts. ${ }^{17}$

Coyne and Smith ${ }^{13}$ have distinguished two types of relationshipfocused coping, which they report as ways of providing support when dealing with diabetes: active engagement and protective buffering. Active engagement is based on support behaviours, such as openly discussing the illness with the partner, asking about partners' feelings and engaging in joint problem-solving strategies. On the other hand, protective buffering refers to support behaviours, including hiding concerns from the partner, making believe that everything is all right and avoiding conflict.
Schokker et $a .^{18}$ found that relationship satisfaction was positively associated with active engagement, and negatively with protective buffering, in both patients and partners.

The aim of this study was: to analyse the relationship among spousal support, social-cognitive variables regarding SMBG (intentions, attitudes, subjective norms, perceived behaviour control, action and coping planning), adherence and glycaemic control; to find out the best predictors of adherence to selfcare behaviours; and, finally, to verify whether positive support was a mediator in the relationship between intention and adherence to SMBG, in patients with type 2 diabetes.

\section{Methods}

Participants. Participants were identified by physicians in health care units, and were eligible for the study if they had a diagnosis of type 2 diabetes of $<12$ months and had a partner. Exclusion criteria included having a cancer diagnosis. The sample included 179 individuals with type 2 diabetes, diagnosed in the past 12 months, with a mean age of 59.6 years $(\mathrm{SD}=10.33) ; 57.5 \%$ were 


\begin{tabular}{|c|c|c|c|c|c|c|c|c|c|c|c|}
\hline & 2 & 3 & 4 & 5 & 6 & 7 & 8 & 9 & 10 & 11 & 12 \\
\hline 1. Intention SMBG & $-0.284^{\star *}$ & $-0.635^{\star *}$ & $0.470^{* *}$ & $0.547^{\star \star}$ & $0.359^{* *}$ & $0.309^{\star *}$ & $0.513^{\star \star}$ & 0.026 & $0.335^{\star *}$ & $0.264^{\star \star}$ & $0.168^{*}$ \\
\hline 2. Attitudes SMBG & - & $0.386^{\star \star}$ & $0.206^{\star *}$ & 0.253 & 0.080 & $0.160^{*}$ & $0.173^{*}$ & -0.068 & 0.087 & $0.158^{*}$ & 0.011 \\
\hline 3. SubNorm SMBG & - & - & $0.183^{*}$ & $0.257^{\star \star}$ & $0.241^{\star \star}$ & $0.208^{\star \star}$ & $0.388^{\star \star}$ & 0.054 & $0.244^{* *}$ & $0.288^{\star *}$ & $0.170^{*}$ \\
\hline 4. Control SMBG & - & - & - & $0.584^{* *}$ & 0.037 & 0.044 & $0.202^{\star *}$ & 0.041 & $0.347^{\star *}$ & 0.065 & -0.033 \\
\hline 5. Planning SMBG & - & - & - & - & $0.282^{* *}$ & $0.181^{*}$ & $0.371^{\star \star}$ & 0.017 & $0.257^{\star *}$ & 0.097 & -0.081 \\
\hline 6. Positive support & - & - & - & - & - & $0.883^{\star *}$ & $0.455^{\star \star}$ & -0.035 & 0.101 & 0.113 & 0.135 \\
\hline 7. Negative support & - & - & - & - & - & - & $0.346^{\star \star}$ & -0.101 & 0.048 & -0.019 & $0.160^{*}$ \\
\hline 8. Adherence: SMBG & - & - & - & - & - & - & - & 0.051 & $0.191^{\star *}$ & 0.100 & $0.183^{*}$ \\
\hline 9. Adherence: exercise & - & - & - & - & - & - & - & - & 0.013 & $0.210^{\star *}$ & -0.087 \\
\hline 10. Adherence: foot care & - & - & - & - & - & - & - & - & - & $-146^{\star}$ & -108 \\
\hline 11. Adherence: diet & - & - & - & - & - & - & - & - & - & - & -0.042 \\
\hline 12. $\mathrm{HbA}_{1 \mathrm{c}}$ & - & - & - & - & - & - & - & - & - & - & - \\
\hline
\end{tabular}

${ }^{*} p<0.05 ;{ }^{* *} p<0.01$. SMBG = self-monitoring of blood glucose; SubNorm = subjective norms.

Table 1. Results of correlations among social-cognitive variables, spousal support and adherence

males, $97.9 \%$ had been married for 33.4 years $(\mathrm{SD}=12.9)$, and $67.7 \%$ had four years of school education.

Procedure. Data were collected in several health centres in the North of Portugal, on the same day as the regular medical appointment. The Ethics Committee of the Health Association in the North of Portugal approved the study and participation was voluntary and confidential. All patients and partners completed an informed consent form to participate in the study. Patients and partners answered the questionnaires separately. A cross-sectional and correlational design was used.

Instruments. Adherence was assessed using the Revised Summary of Diabetes Self-Care Activities Measure (RSDSCA), ${ }^{19}$ a self-report questionnaire that consists of 19 items grouped into 5 dimensions (general diet, specific diet, exercise, foot care and blood glucose control). Higher results indicate higher adherence to the respective behaviours. Cronbach's alphas of subscales ranged from $0.61-0.96$, and the total scale has an alpha of 0.61.

Social-cognitive variables were assessed using the Planned Behavior Questionnaire - Self-Monitoring of Blood Glucose (PBQ-SMBG), ${ }^{20}$ which is based on TPB. This instrument is composed of 22 items, grouped into 5 subscales: intentions, attitudes, subjective norms, perceived behaviour control, and action and coping planning. Cronbach's alphas ranged from 0.67-0.98. Higher results in each subscale indicate higher use of the social-cognitive variables regarding SMBG.

Spousal support was assessed using the Multidimensional Diabetes Questionnaire (MDQ) ${ }^{21}$ that includes 41 items and 3 subscales: perceptions of diabetes and related social support in general; perceptions of self-care activities, namely, frequency of social incentives related to self-care activities; and self-efficacy and outcome expectancies. In this study, only the third subscale was used, which assesses the frequency of spouse support (positive and negative) behaviours in diabetes self-care (medication, diet, glycaemic control, exercise and foot care adherence). Cronbach's alpha for positive support was 0.85 and 0.77 for negative support. Higher scores indicate higher levels of positive or negative support behaviours respectively.

Glycaemic control was assessed by glycosylated haemoglobin $\left(\mathrm{HbA}_{1 \mathrm{c}}\right)$.

Data analysis. In order to analyse the relationship among social-cognitive variables, spousal support and adherence, Pearson's correlation coefficient (r) was used. To determine the best predictors of adherence, a multiple regression analysis (method enter) was conducted. In order to determine if positive support mediated the relationship between intention to perform SMBG and adherence to this self-care behaviour, a mediation analysis was conducted following Baron and 


\section{Original article}

Partner support, social-cognitive variables and their role in adherence to SMBG in type 2 diabetes

Kenny's approach. ${ }^{22}$ This includes four conditions for determining if an independent variable affects a dependent variable through a mediator variable: (1) there is an association of the independent variable with the mediator; (2) there is an association of the mediator with the dependent variable; (3) there is an association of the independent variable with the dependent variable; (4) the association of independent and dependent variables reduces significantly or disappears when the mediator variable is added to the equation.

\section{Results}

Relationships among social-cognitive variables, spousal support, adherence and glycaemic control. The results in Table 1 show positive partner support to be positively associated with intention to perform SMBG, subjective norms, action and coping planning and adherence to SMBG. In turn, negative support was also positively associated with intention to perform SMBG, subjective norms, action and coping planning, adherence to SMBG and glycaemic control $\left(\mathrm{HbA}_{1 \mathrm{c}}\right)$. Also, adherence to SMBG was positively associated with intention, attitudes, subjective norms, perceived behaviour control, and action and coping planning. High levels of $\mathrm{HbA}_{1 \mathrm{c}}$ (low glycaemic control) were positively correlated with partner negative support, intention to perform SMBG, subjective norms and adherence to SMBG.

Predictors of adherence to SMBG. Table 2 shows positive partner support, as well as intention to perform SMBG, as significant predictors of adherence to SMBG. The model explained $36.6 \%$ of the variance.

Positive partner support as a mediator of the relationship between intention to perform SMBG and adherence to SMBG. Since positive

\begin{tabular}{l|l|l|l} 
& $\boldsymbol{\beta}$ & $\mathbf{t}$ & $\mathbf{p}$ \\
\hline Intention SMBG & 0.181 & 2.68 & $0.008^{* *}$ \\
\hline Attitudes SMBG & 0.002 & 0.027 & 0.978 \\
\hline Subjective norms SMBG & -0.138 & -0.63 & 0.104 \\
\hline Perceived behaviour control SMBG & -0.001 & -0.016 & 0.987 \\
\hline Planning SMBG & -0.017 & 0.899 & 0.370 \\
\hline Positive support & 0.09 & 3.92 & $0.000^{\star *}$ \\
\hline Negative support & -0.058 & -1.59 & 0.113 \\
\hline $\mathbf{R}^{2}$ & 0.391 & & \\
\hline Adj $\mathbf{R}^{2}$ & 0.366 & & \\
\hline
\end{tabular}

${ }^{*} \mathrm{p}<0.05 ;{ }^{* *} \mathrm{p}<0.01$

Table 2. Predictors of adherence to self-monitoring of blood glucose (SMBG)

\begin{tabular}{l|l|l|l|l} 
Step & Adj $\mathbf{R}^{\mathbf{2}}$ & $\boldsymbol{\beta}$ & $\mathbf{t}$ & $\mathbf{p}$ \\
\hline $\begin{array}{l}\text { 1. Path c } \\
\text { IV: Intentions } \\
\text { DV: Adherence to SMBG }\end{array}$ & 0.259 & 0.513 & 8.047 & 0.00 \\
\hline $\begin{array}{l}\text { 2. Path a } \\
\text { IV: Intentions } \\
\text { DV: Positive support }\end{array}$ & 0.124 & 0.359 & 5.166 & 0.00 \\
\hline $\begin{array}{l}\text { 3. Path b } \\
\text { IV: Positive support } \\
\text { DV: Adherence to SMBG }\end{array}$ & 0.370 & 0.357 & 5.646 & 0.00 \\
$\begin{array}{l}\text { Path c' } \\
\text { IV: Intentions } \\
\text { M: Positive support } \\
\text { DV: Adherence to SMBG }\end{array}$ & & 0.388 & 6.135 & 0.00
\end{tabular}

Table 3. Results of positive partner support as a mediator in the relationship between intention and adherence to self-monitoring of blood glucose (SMBG)

support predicted adherence to of intentions on positive support SMBG, a mediation analysis was con- (mediator) (path a), was also signifiducted to determine whether positive cant $(\beta=0.359 ; \mathrm{p}<0.00)$; the effect of support mediates the relationship positive support on adherence to between intention to perform SMBG SMBG (path b) was significant and adherence to SMBG.

The four steps of Baron and Kenny ${ }^{22}$ were confirmed in the regression analysis, as shown in Table 3. The effect of intentions on adherence to SMBG (path c) was significant $(\beta=0.513 ; \mathrm{p}<0.00)$; the effect $(\beta=0.357 ; p<0.00)$. Finally, the effect of positive support on the relationship between intentions and adherence to SMBG (path c') was also significant $(\beta=0.388 ; \mathrm{p}<0.00)$.

Figure 2 shows the results of the mediation analysis, revealing a partial 


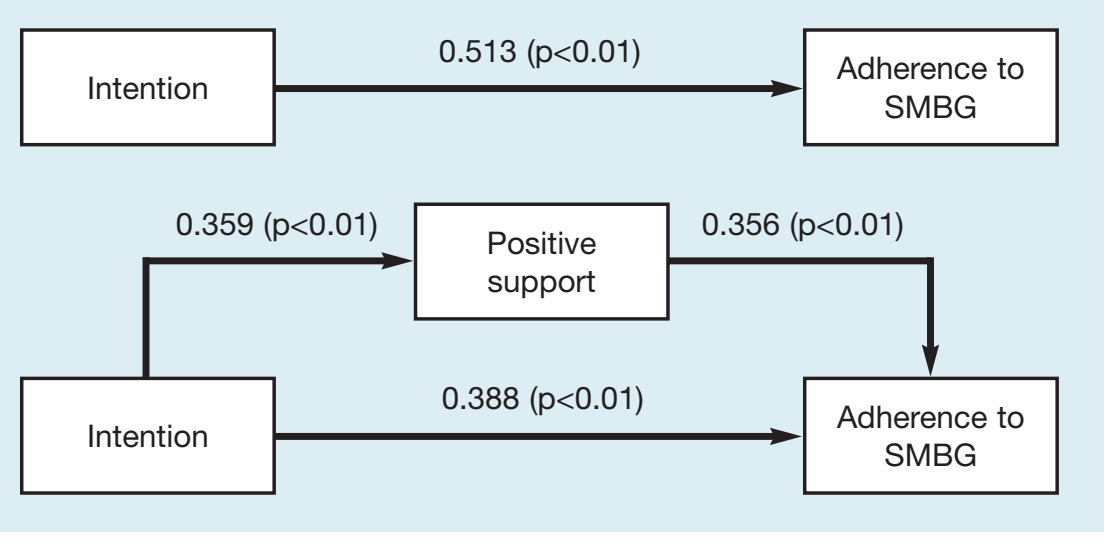

Figure 2. Mediation analysis

mediation of positive partner support in the relationship between intention and adherence to SMBG. In fact, there is a statistically significant reduction in the effect of intention on adherence to SMBG upon the addition of positive support to the model.

\section{Discussion}

The literature is vague with regard to studies aimed at determining the relationship between social-cognitive variables regarding SMBG and adherence to SMBG. However, TPB is considered a relevant model in the prediction and explanation of health-related behavioural changes, ${ }^{6-9}$ supporting this study's findings.

Partners' support has been shown to be indispensable and determinant in diabetes self-care. ${ }^{14,23-25}$ In fact, support from the partner has been found to be the most important source of support during illness episodes $^{23}$ providing informational, tangible and emotional support. ${ }^{26}$ LaGreca et al. ${ }^{27}$ in a study that compared support provided by family and friends in adolescents with diabetes, found family support to be directly involved in more instrumental support, related to diabetes management, such as insulin injections, diet and SMBG.

Illnesses that require a complex regimen, such as diabetes, may need more frequent dyadic coping between spouses that requires a change in lifestyle (i.e. diet and exercise) and is best accomplished by the couple..$^{28}$ In our study, the results highlight the importance of partners' positive support as praise, encouragement, and reminding the patient to adopt diabetes self-care behaviours. These positive reinforcements lead to a higher intention to monitor glucose and to a higher perception of control regarding this behaviour. Patients who perceive positive support from partners often develop an action and coping plan, to help them in the management of obstacles and constraints regarding SMBG. The help of a collaborative partner may be paramount in this case. ${ }^{13,29-31}$ In fact, van Dam et al. ${ }^{32}$ in their review of several studies about social support in diabetes, found that social support influences the management and outcomes of diabetes care through different ways: patients' social network is an important source of information and plays a leading role in the diagnosis, treatment and management, and in dealing with expectations and complications of diabetes. This fact may be important to health professionals, emphasising the need to include partners in patients' treatment, while working on beliefs regarding diabetes that influence social-cognitive constructs, since they have extreme importance in decision making about self-care behaviours in diabetes patients. Besides emotional support, social support may lead to better coping strategies and better structure in daily routines, empowering the patient to deal with possible barriers that may occur regarding SMBG. Plus, according to the results, the importance of behaving in accordance with significant others' expectations is evident.

Therefore, in this sample, both positive and negative support were associated with the patient's intention to monitor glucose, reiterating the importance of partner support, either positive or negative. According to these results, the decision to perform SMBG is based on intentions, expectations of significant others, the perception of control, and action and coping planning to perform SMBG. It is important to emphasise, in diabetes care, how the patient intends to monitor glucose, and plans to perform SMBG, and how much control the patient feels they have regarding this task. Thus, diabetes education should include eliciting the patient's beliefs about self-care, since they are the basis of intention and consequently performance of SMBG. Furthermore, partners may have an impact on how patients manage their diabetes and on adherence to self-care behaviours. Since partners are paramount in a patient's adherence to treatment, they must be involved in the therapeutic process to learn how to provide suitable support in diabetes management. In fact, in a study involving type 2 diabetes patients, Bastos $^{33}$ found that those who attended medical appointments with their spouse regularly showed more adherence and better diabetes outcomes, when compared to patients who attended medical appointments without their partners. As a result, it comes as no surprise that positive support was 
also found to be a mediator in the relationship between intentions and adherence to SMBG. This result has major implications for practice. Health professionals must be aware that the involvement of partners in diabetes education helps patients' management of the disease and promotes their intention to adhere and, consequently, their SMBG.

It would be interesting, in the future, to design a study with type 2 diabetes patients who have no partners - since the literature shows that patients without the support of a partner reveal lower adherence and higher levels of $\mathrm{HbA}_{1 \mathrm{c}}{ }^{34}$ - and compare them with patients with partners regarding the performance of SMBG.

\section{Declaration of interests}

The study was funded by Fundação para a Ciência e Tecnologia, Portugal.

\section{References}

1. International Diabetes Federation. www.idf.org/atlasmap/atlasmap [accessed 4 Nov 2011].

2. Portuguese Society of Diabetology. www.minsaude.pt/NR/rdonlyres/ 219DAD78-CD 13-43CE-9221-427 44B24176C/O/Estudoprevalencia DiabetesemPortugal.pdf [accessed 26 Nov 2010].

3. Observatório Nacional da Diabetes. www.portaldasaude.pt/NR/rdonlyr es / 4747F2BE-D534-4983-9A94C5B7066C9731/0/i012326.pdf [accessed 12 Sept 2010].

4. Rubin RR. Adherence to pharmacological therapy in patients with type 2 diabetes mellitus. Am J Med 2005;118(Suppl 5A):27S-34S.

5. Yeaw J, et al. Comparing adherence and persistence across 6 chronic medication classes. J Managed Care Pharmacy 2009;15:728-40.

6. Ajzen I, Manstead ASR. Changing health-related behaviors: an approach based on the theory of planned behavior. In: van den Bos V, et al, eds. The scope of social psychology: Theory and applications. New York: Psychology Press, 2006;43-63.

7. Araújo-Soares V, et al. Predicting changes in physical activity among adolescents: the role of self-efficacy, intention, action planning and coping planning. Health Educ Res 2009;24:128-39.

8. Darker C, et al. An intervention to promote walking amongst the general population based on an extended theory of planned behavior: a waiting list randomized controlled trial. Psychol Health 2010;25:71-88.

9. Gatt S, Sammut R. An exploratory study of predictors of self-care behavior in persons with type 2 diabetes. Int J Nurs Stud 2008;45: 1525-33.

10. Ajzen I. http://people.umass.edu/ aizen/pdf/tpb.measurement.pdf [accessed 21 Nov 2010].

11. Ajzen I. The Theory of Planned Behavior. Organ Behav Hum Decis Process 1991;50:179-211.

12. Ajzen I. From intentions to actions: a theory of planned behavior. In: Kuhi J, Beckmann J, eds. Actioncontrol: from cognition to behavior. Heidelberg: Springer, 1985;11-39.

13. Coyne JC, Smith DA. Couples coping with a myocardial infarction: a contextual perspective on patient self-efficacy. J Fam Psychol 1994; 8:43-54.

14. Trief PM, et al. Describing support: a qualitative study of couples living with diabetes. Fam Syst Health 2003; 21:57-67.

15. Chesla CA, et al. Family predictors of disease management over one year in Latino and European American patients with type 2 diabetes. Fam Process 2003;42:375-90.

16. Fisher L, et al. The family and disease management in Hispanic and Euro-American patients with type 2 diabetes. Diabetes Care 2000;23: 267-72.

17. Stephens MA, et al. Spouses use of social control to improve diabetic patients' dietary adherence. Fam Syst Health 2010;28:199-208.

18. Schokker MC, et al. Support behavior and relationship satisfaction in couples dealing with diabetes: main and moderating effects. JFam Psychol 2010;24:578-86.

19. Toobert DJ, et al. The Summary of Diabetes Self-Care Activities Measure. Diabetes Care 2000;23:943-50.

20. Pereira MG, et al. Research version of the Planned Behavior Questionnaire - Self-Monitoring of Blood Glucose. University of Minho, School of Psychology, 2008.

21. Talbot F, et al. The assessment of dia- betes-related cognitive and social factors: the Multidimensional Diabetes Questionnaire. J Behav Med 1997; 20:291-312.

22. Baron RM, Kenny DA. The moderator-mediator variable distinction in social psychological research: conceptual, strategic, and statistical considerations. J Pers Soc Psychol 1986;51:1173-82.

23. Trief PM, et al. Family environment, glycemic control, and the psychosocial adaptation of adults with diabetes. Diabetes Care 1998;21:241-5.

24. Trief, PM, et al. A prospective analysis of marital relationship factors and quality of life in diabetes. Diabetes Care 2002;25:1154-8.

25. Garay-Sevilla ME, et al. Adherence to treatment and social support in patients with NIDDM. I Diabetes Complications 1995;9:81-6.

26. Berg CA, Upchurch R. A developmental-contextual model of couples coping with chronic illness across the adult life span. Psychol Bull 2007;133:920-54.

27. LaGreca AM, et al. I get by with a little help from my family and friends: adolescents' support for diabetes care. J Pediatr Psychol 1995;20:449-76.

28. Gallant MP. The influence of social support on chronic illness self-management: a review and directions for research. Health Educ Behav 2003; 30:170-95.

29. Trief PM, et al. The marital relationship and psychosocial adaptation and glycemic control of individuals with diabetes. Diabetes Care 2001; 24:1384-9.

30. Trief PM, et al. The relationship between marital quality and adherence to the diabetes care regimen. Ann Behav Med 2004;27:148-54.

31. Fisher L. Family relationships and diabetes care during the adult years. Diabetes Spectr 2006;19:71-4.

32. van Dam HA, et al. Social support in diabetes: a systematic review of controlled intervention studies. Patient Educ Couns 2005;59:1-12.

33. Bastos F. O papel das esposas na adesão ao regime terapêutico no diabético tipo 2. In: Leal I, et al., eds. Actas do $6^{\circ}$ Congresso Nacional de Psicologia da Saúde. Lisboa: ISPA, 2006;571-7.

34. Daly J, et al. An assessment of attitudes, behaviors, and outcomes of patients with type 2 diabetes. $J \mathrm{Am}$ Board Fam Med 2009;22:280-90. 